\title{
Reflexões sobre a implementação do PNAIC na Educação Infantil: tensões e riscos à docểncia e à infância
}

\author{
Fernanda Theodoro Roveri* \\ Secretaria Municipal de Educação de Campinas \\ Caroline Duarte** \\ Secretaria Municipal de Educação de Campinas
}

Resumo Os atuais programas de alfabetização de crianças no Brasil emergiram em um contexto de tensões e de controle dos índices de analfabetismo no país, fazendo com que tanto o Ensino Fundamental quanto a Educação Infantil assumissem a tarefa de alfabetizar as crianças. Nesse sentido, torna-se urgente a reflexão acerca das concepções de ensino, de avaliação, de infância e de formação docente disseminadas nesses programas. O objetivo desse artigo é discutir a implementação do Pacto Nacional pela Alfabetização na Idade Certa (PNAIC) na Educação Infantil (Portaria $n^{\circ}$ 826, de 7 de julho de 2017), tendo como objetos de análise os materiais de formação, os discursos dirigidos aos professores e os dilemas que envolveram sua execução. Busca-se, deste modo, contribuir com as discussões acerca das especificidades da Educação Infantil e da docência nesta primeira etapa da Educação Básica, propondo, assim, que a diversidade de práticas cotidianas com as crianças pequenas e seus protagonismos sejam valorizados.

PALAVRAS-CHAVE: Alfabetização; Educação Infantil; Formação de professores. 


\title{
Reflections on the implementation of the PNAIC in Early Childhood Education: tensions and risks to teaching and childhood
}

\begin{abstract}
Current children's literacy programs in Brazil have emerged in a context of tensions and control of illiteracy rates in Brazil, with both the first years of elementary school and early childhood education being responsible for literacy among children. In this sense, it is urgent to reflect on the conceptions of teaching, assessment, childhood and teacher education disseminated in these programs. The purpose of this article is to discuss the implementation of the National Pact for Literacy in the Right Age (PNAIC) in early childhood education (Ordinance $\mathrm{n}^{\circ}$ 826, July 7, 2017). The objects of analysis are training materials, discourses addressed to teachers and the dilemmas that involved its execution. In this way, we seek to contribute to the discussions about the specificities of Early Childhood Education and teaching in this first stage of $\mathrm{Ba}-$ sic Education, thus proposing that the diversity of daily practices with young children and their protagonism be valued.
\end{abstract}

KEYWORDS: Literacy; Early childhood education; Teacher training.

\section{Introdução}

O Pacto Nacional pela Alfabetização na Idade Certa (PNAIC) é um programa de formação continuada de professores e faz parte da Política Nacional de Formação de Profissionais do Magistério da Educação Básica (Decreto no 6.755, de 29 de janeiro de 2009). O PNAIC foi instituído pelo Ministério da Educação por meio da Portaria no 867, de 4 de julho de 2012 e está atrelado à quinta meta estruturante do Plano Nacional de Educação (PNE), a qual pretende garantir "a alfabetização de todas as crianças, de forma plena, até o final do ciclo de alfabetização - correspondente ao terceiro ano do ensino fundamental - durante os primeiros cinco anos de vigência do plano"(BRASIL, 2014, p. 27). ${ }^{1}$

No ano de 2017, o MEC agregou a Educação Infantil ao PNAIC por meio da Portaria no 826, de 7 de julho de 2017, sem a devida discussão entre os diversos segmentos da sociedade e a participação dos profissionais da educação ${ }^{2}$. $\mathrm{O}$ texto da Portaria destaca, no Art. $2^{\circ}$, que as ações no programa passam a ter

foco nos estudantes da pré-escola e do ensino fundamental, cabendo aos professores, coordenadores pedagógicos, gestores escolares e gestores públicos uma responsabilidade compartilhada no alcance do direito da criança de escrever, ler com fluência e dominar os fundamentos da Matemática no nível recomendável para sua idade (BRASIL, 2017).

Entre o final do ano de 2017 e início de 2018, diversos municípios brasileiros fizeram a adesão da Educação Infantil ao PNAIC, muitos deles sem a necessária clareza quanto o seu funcionamento e a compreensão dos objetivos por parte de gesto- 
res, professores(as) da Educação Infantil e seus familiares, o que nos leva a questionar se o programa significaria uma ameaça de escolarização das crianças pequenas, a fragmentação das práticas, a possibilidade de um currículo voltado para resultados exitosos em avaliações externas, além da ameaça à autoria docente.

À vista disso, é necessário problematizarmos o que se quer alcançar quando se firma um pacto pela alfabetização de crianças de 3 a 5 anos de idade? Quem são os participantes desse pacto e quais as atribuições de cada um? O que se deseja que as crianças aprendam? Para que? Como e o que será ensinado? Quem se responsabilizará pelos resultados alcançados? E, ainda, quais concepções de infância, de alfabetização e de docência são assumidas?

É importante destacarmos que, no decorrer destas análises, não defendemos que as crianças pequenas não possam se interessar pelas práticas sociais de leitura e escrita ou que os professores(as) não devam participar de formações continuadas. Acreditamos que os percursos formativos são possíveis de serem vividos de diversas maneiras, (re) apropriados pelos sujeitos, tensionados coletivamente e ressignificados nos cotidianos. O que queremos aqui problematizar são os modos pelos quais as políticas educacionais se dirigem aos professores(as) e às crianças, de maneira que possam ser vistas como frutos de embates, disputas e concepções nem sempre aceitas ou compreendidas por todos os segmentos educativos.

Levando em conta esses aspectos, discutiremos primeiramente o contexto de luta pelo reconhecimento das especificidades da Educação Infantil e pela garantia dos direitos das crianças, analisando de que maneiras as políticas de avaliação da Educação Básica interferem na organização do trabalho na Educação Infantil. Em seguida, problematizaremos o processo de implementação do PNAIC e as políticas de formação de professores(as) alfabetizadores(as). Por fim, apresentaremos uma discussão acerca dos cadernos do PNAIC da Educação Infantil, tendo como eixo de análise as concepções de docência neles manifestadas. Buscaremos, assim, contribuir para o debate em torno da defesa de uma Educação Infantil que respeite a diversidade de práticas e os protagonismos de seus atores.

\section{A Educação Infantil na luta pela sua especificidade}

As políticas brasileiras de atendimento de bebês e crianças pequenas em creches e pré-escolas são oriundas de uma tradição assistencialista e escolarizante da infância. Na história desse atendimento, Kuhlmann Jr. (1998) identifica que as propostas destinadas às classes populares tiveram, em geral, um caráter educacional compensatório, marcado por práticas de submissão tanto das crianças quanto de suas famílias.

Um longo e tortuoso processo, erigido por embates entre grupos sociais e políticos com diferentes concepções de infância e de educação, delineou as formas de organização das instituições de Educação Infantil no País nas últimas décadas.

A obrigatoriedade da oferta da educação pública em creches e pré-escolas foi resultado de importantes lutas, nos anos de 1980, pela garantia dos direitos da infância. As discussões de diversos grupos sociais - professores, entidades acadêmicas, 
pesquisadores, mulheres trabalhadoras, movimento feminista, dentre outros - lançaram um olhar para as especificidades do trabalho educativo em creches e pré-escolas e o direito das crianças e de suas famílias a frequentarem esse espaço público e gratuito. Esse reconhecimento orientou os documentos oficiais das décadas seguintes, trazendo como eixos principais da Educação Infantil a relação indissociável entre o cuidar e educar e o direito à brincadeira, de modo a contestar as propostas assistencialistas e escolarizantes em creches e pré-escolas.

Nesse contexto, o documento "Diretrizes Curriculares Nacionais para a Educação Infantil” (DCNEI), fixado pelo MEC/SEB em 2009 após amplo debate com a sociedade, reconhece os direitos das crianças e dos bebês e o dever do Estado em garantir a oferta de vagas em creches e pré-escolas. As Diretrizes também valorizam as dimensões éticas, políticas e estéticas do trabalho pedagógico, caracterizando a especificidade dos bebês e das crianças pequenas, vistos como sujeitos históricos. Nesse sentido, o Art. 13 das DCNEI estabelece que

$\mathrm{Na}$ transição para o Ensino Fundamental a proposta pedagógica deve prever formas para garantir a continuidade no processo de aprendizagem e desenvolvimento das crianças, respeitando as especificidades etárias, sem antecipação de conteúdos que serão trabalhados no Ensino Fundamental (BRASIL, 2009, grifos nossos).

As análises de Kuhlman Jr. (1999) acerca das funções da Educação Infantil destacam que esta não deve esquivar-se da preocupação com a articulação com o Ensino Fundamental, já que as crianças pequenas se interessam em aprender a ler, a escrever e a contar. Mas, em sua visão, é necessário haver clareza quanto ao caráter da Educação Infantil e, principalmente, ter a criança como o ponto de partida para orientar o trabalho e não aquilo que será esperado dela quando ingressar no Ensino Fundamental (KUHLMAN Jr., 1999).

No entanto, como discutem Stieg e Araújo (2017), inúmeras políticas de alfabetização e de avaliação em larga escala adentram os currículos da Educação Infantil sem que necessariamente levem em conta as crianças e suas especificidades. A partir de uma perspectiva histórica, os autores mostram que as políticas de alfabetização para a infância no Brasil, lançadas entre os anos de 1996 a 2016, apresentam perspectivas utilitaristas, mercadológicas e escolarizantes de alfabetização, reflexos de um Estado cada vez mais refém do poder econômico excludente e voltado para a lógica do desempenho e dos resultados.

Essa lógica evidencia-se no compromisso que o Brasil assumiu com órgãos internacionais de elevar o Índice de Desenvolvimento da Educação Básica (Ideb) para 6,0 até o ano de 2022, a fim de poder participar da economia financeira mundial. A Educação Básica tornou-se o lugar de preparação para as avaliações externas, quando, na verdade, deveria constituir-se um espaço para além do ensino do ler e do escrever, visto que a educação

[...] tem por responsabilidade compartilhar as heranças históricas e culturais de modo com que as crianças possam aos poucos renová-las tendo em vista um mundo comum e público, diferente de 
uma concepção de educação concebida como um investimento privado ou uma perspectiva pragmática de seus meios e fins (STIEG e ARAÚJO, 2017, p.71).

A intensificação de programas de alfabetização de crianças, disseminados por todo País pelo MEC desde os anos de 1996 foi acompanhada de políticas de formação de professores alfabetizadores, tais como Parâmetros Curriculares Nacionais - PCNs (1996), Documento Alfabetizar com textos (1999), Programa de Formação de Professores Alfabetizadores - PROFA (2001-2003), Pró-Letramento (2006-2012) e Pacto Nacional para Alfabetização na Idade Certa - PNAIC (2013), este último estendido para a Educação Infantil em 2017. Conforme alertam Stieg e Araújo (2017), as maciças campanhas pela alfabetização fazem recair às professoras e às crianças a função e o dever de diminuir ou erradicar o analfabetismo brasileiro. Além disso, passam a encarregar a Educação Infantil de realizar o trabalho antecipado de alfabetização, visto que as crianças já deverão estar preparadas, aos 8 anos de idade, para os testes em larga escala.

Ao analisar as políticas de avaliação para a Educação Infantil no Brasil, Sousa (2014) identifica um campo de disputas entre diversos segmentos - representantes da gestão pública, entidades acadêmicas, movimentos sociais, empresariado e professores(as) - no que diz respeito às concepções e aos critérios para uma educação de qualidade. A autora chama a atenção para um movimento de institucionalização da avaliação da Educação Infantil ao Sistema Nacional de Avaliação da Educação Básica (Saeb), já previsto no Plano Nacional de Educação do decênio 2001-2011 e reafirmado no mesmo documento de 2014-2024. A referida lei prevê, na meta 1 do Art. 2o., a integração da Educação Infantil ao sistema de avaliação da educação básica, a ser realizada

[...] a cada 2 (dois) anos, com base em parâmetros nacionais de qualidade, a fim de aferir a infraestrutura física, o quadro de pessoal, as condições de gestão, os recursos pedagógicos, a situação de acessibilidade, entre outros indicadores relevantes (BRASIL, 2014, Art. 2o, Meta 1, item1.6).

De acordo com Sousa (2014), se por um lado há o reconhecimento da avaliação na Educação Infantil como um dos fatores para se buscar a qualidade do atendimento, por outro lado ainda não existe um acordo acerca das dimensões e dos critérios necessários para aferir esta qualidade. A autora identifica, assim, um campo de disputas no qual alguns grupos priorizam a avaliação das condições de oferta da Educação Infantil - enfatizando os indicadores de acesso, insumos e processos - e outras instâncias, juntamente com as propostas do MEC, que privilegiam o desempenho de alunos, considerando as habilidades cognitivas e as competências das crianças como indicadores fundamentais para a avaliação (SOUSA, 2014).

Exemplo disso é a Avaliação Nacional de Alfabetização (ANA), criada em 2013 e articulada ao PNAIC. A ANA está integrada ao Sistema de Avaliação da Educação Básica (SAEB), juntamente com a Prova Brasil e a Avaliação Nacional da Educação Básica (ANEB), consistindo em uma avaliação de larga escala, censitária e externa aos sistemas públicos de ensino. Sua aplicação é anual para os alunos de 8 anos 
de idade, com vistas a assegurar que todos eles estejam alfabetizados até o final do $3^{\circ}$. Ano do Ensino Fundamental.

Para Dickel (2016), o fato de a ANA constituir o SAEB e integrar as ações do PNAIC produz consequências singulares no cenário das políticas curriculares e de avaliação. Conforme esclarece a autora, enquanto as duas outras avaliações da Educação Básica - Prova Brasil e ANEB - voltam-se ao controle do cumprimento das metas do Plano de Desenvolvimento da Educação ${ }^{3}$, a ANA tem como foco o controle do trabalho pedagógico e a responsabilização da escola e do(a) professor(a), já que funciona como instrumento de monitoração da aprendizagem das crianças que terminam o primeiro ciclo do Ensino Fundamental. Outro diferencial da ANA em relação às demais avaliações é que seu conteúdo e objetivos estão atrelados à formação recebida pelos(as) professores(as) no curso do PNAIC, o que significa a sujeição dos docentes às pressões e a culpabilização pelos resultados de seus alunos.

Embora essa avaliação não se aplique diretamente à Educação Infantil, é notável seu potencial de influência no funcionamento e na organização do trabalho em creches e pré-escolas, além da pressão para que se escolarize essa primeira etapa da Educação Básica. Isso pode ser percebido a partir da ampliação, em 2017, do alcance do PNAIC, mediante o discurso de que a matemática, a escrita e a leitura fluente devem contemplar os direitos de aprendizado das crianças a partir dos 3 anos de idade. Nesse sentido, concordamos com Sousa $(2014$, p. 83) quando afirma que

$$
\begin{aligned}
& \text { o que se quer realçar é que este Pacto e a avaliação a ele associada } \\
& \text { podem vir a ter reflexos na própria dinâmica de trabalho da educa- } \\
& \text { ção infantil, condicionando os processos de letramento e alfabetiza- } \\
& \text { ção, introduzindo desde esta etapa da escolarização a preocupação } \\
& \text { em preparar os alunos para os testes, corroborando a noção de me- } \\
& \text { dida como sinônimo de avaliação. }
\end{aligned}
$$

A ampliação do acesso à Educação Infantil, nas últimas décadas, vem acompanhada das tensões e dos debates em torno da qualidade no atendimento oferecido, o qual deveria garantir o acolhimento adequado das crianças e dos bebês e o respeito às suas necessidades e especificidades, por meio de estruturas materiais e humanas adequadas. No entanto, a maior parte das políticas públicas educacionais concebe a avaliação, o currículo e os programas de formação de professores como elementos coercitivos, de controle, de seleção e de classificação.

Quando olhamos para um programa de formação continuada como o PNAIC, é necessário analisarmos não apenas os objetivos, os conteúdos, os referenciais teóricos, as concepções de infância e de docência subjacentes a ele, mas também os interesses políticos e os conflitos presentes em sua elaboração, bem como as estratégias de implementação por parte do poder público. 


\section{A implementação do PNAIC na Educação Infantil e sua es- trutura de formação}

A crescente visibilidade, nos meios de comunicação, de dados relativos ao analfabetismo brasileiro de jovens, crianças e adultos, bem como de seus conhecimentos escassos na matemática, traz como questão urgente a busca por soluções ao que se identifica como ineficácia escolar. Os discursos relativos ao fracasso corroboram para a defesa de programas específicos de capacitação de professores, concebidos como os principais responsáveis por sanar os problemas de aprendizado dos alunos nas áreas de leitura, escrita e cálculo. Sem dúvida, a emergência de um pacto nacional pela alfabetização se justifica nesse contexto e traz, como consequência, uma expectativa de controle e vigilância sobre o processo pedagógico escolar (DICKEL, 2016).

Uma das características marcantes nos programas de formação de professores é o cumprimento de metas e objetivos para além do campo educacional. $\mathrm{Ob}$ servamos que, desde o final dos anos de 1990, a conjuntura política e econômica do mundo e do Brasil interfere na elaboração desses programas (FERNANDES, 2015). A estrutura de muitos deles tem como objeto de controle o processo pedagógico, determinando o que e como o(a) professor(a) deve ensinar em sala de aula. As bases desse mecanismo de controle sustentam-se a partir de um sistema de responsabilização. Conforme salienta Freitas (2012), esse sistema envolve três elementos: os testes para os estudantes, a divulgação pública do desempenho da escola e o sistema meritocrático de recompensas e sanções. Esse sistema veicula a ideia de que a igualdade de oportunidades é oferecida a todos, sendo os resultados dependentes dos esforços e das capacidades de cada um.

Nesse sentido, a avaliação incide nos resultados dos esforços docentes, constatados a partir daquilo que os alunos manifestam ter aprendido. Conforme problematiza Luna (2016), não é simplesmente por meio de uma transposição didática ou uma suposta competência do professor em apropriar-se dos saberes científicos e adaptá-los de maneira eficaz aos seus alunos que se garantirá o sucesso pedagógico, é preciso ter em conta que o processo de ensino está submetido a uma ordem institucional e que a escola tem um caráter dinâmico.

É presumível, destarte, que um pacto para a alfabetização de todas as crianças que frequentam a Educação Básica brasileira prescinda de uma excessiva capacitação, de modo com que o maior número de professores seja atingido e toda gama de conteúdos necessários para que as ações desse pacto se realizem lhes seja acessível. O programa de formação do PNAIC oferecido para o Ensino Fundamental é estruturado por 10 cadernos temáticos, além de mais um caderno de apresentação e outro dirigido aos gestores. $\mathrm{Na}$ Educação Infantil, o programa é estruturado por 9 cadernos temáticos sendo um de apresentação, contendo em média 120 páginas cada um deles ${ }^{4}$.

Fernandes (2015), ao analisar a perspectiva de formação de professores circunscrita no PNAIC, problematiza tanto o uso excessivo de materiais produzidos para os cursos quanto uma estrutura fechada de formação voltada aos docentes de todo o país, destacando que a dissociação da "[...] experiência autoral de diálogo entre teoria 
e prática pode incorrer no perigo de viabilizar a manutenção de velhos entendimentos sobre alfabetização e suas práticas pedagógicas conhecidas pelos professores" (FERNANDES, 2015, p. 915).

Emilião (2017) discute a implementação da formação continuada do PNAIC tendo como referência uma pesquisa realizada com um grupo de professores -alfabetizadores da rede pública da Região Metropolitana do Rio de Janeiro. A autora destaca o quanto a estrutura do programa é fortemente hierárquica. O tipo de formação oferecido pelo PNAIC é de efeito cascata, do qual participam coordenadores gerais, supervisores e formadores regionais, coordenadores municipais, orientadores de estudos e professores alfabetizadores, conforme podemos perceber no esquema elabo-

Figura 1 - Estrutura de Gestão e Formação do PNAIC

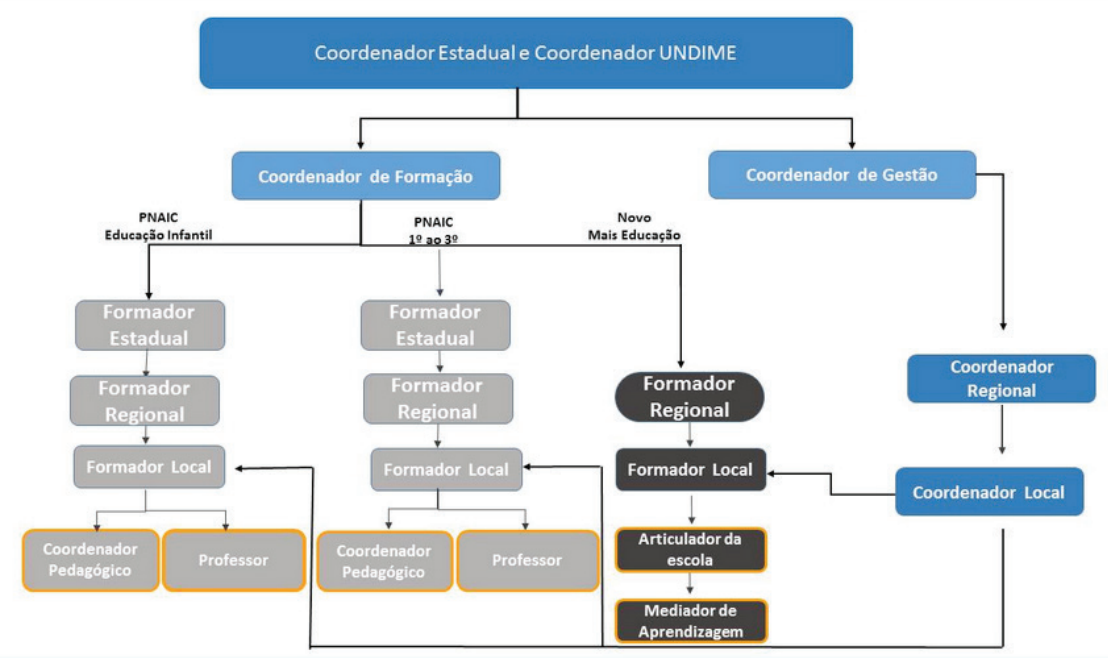

Fonte: http://pacto.mec.gov.br/estrutra-de-gestao-e-formacao

rado pelo MEC:

O "Caderno de Apresentação" do PNAIC da Educação Infantil esclarece que seu conteúdo faz parte de um projeto intitulado "Leitura e Escrita na Educação Infantil", desenvolvido desde 2008 pela Universidade Federal de Minas Gerais (UFMG), a Universidade Federal do Rio de Janeiro (UFRJ) e a Universidade Federal do Estado do Rio de Janeiro (UNIRIO). De acordo com a equipe, o projeto teve como ponto de partida os questionamentos sobre a função da Educação Infantil, o acesso das crianças à cultura escrita e a formação de leitores, bem como de questionamentos acerca do que as crianças de zero a cinco anos podem ler e escrever nas creches e pré -escolas. No ano de 2013 a equipe organizadora firmou uma parceria com a Coordenação Geral de Educação Infantil (COEDI) do MEC, que aprovou o financiamento do projeto com vistas à sua utilização nas políticas públicas para a Educação Infantil.

De acordo com as organizadoras, o projeto mostrou-se exitoso por extrapolar o campo acadêmico e de formação de professores. O seu depoimento mostra que 
o grupo também participou da elaboração da Base Nacional Comum Curricular e das demais políticas educacionais para a Educação Infantil:

Educação Infantil, a formulação de diretrizes para a constituição de acervos de livros para crianças de zero a seis anos, imprimiram, ao grupo de coordenação e aos inúmeros pesquisadores que dele participaram, um papel central de agentes políticos (BAPTISTA, 2018).

No entanto, esse suposto êxito apontado pelas organizadoras se descortina mais adiante quando estas mesmo manifestam, publicamente, no documento "Carta às professoras de Educação Infantil", o desacordo com a parceria firmada com o MEC e as fragilidades da política de formação do PNAIC. Nesta carta ficam visíveis os pontos principais de discordância e as demandas do projeto que não foram atendidas pelo MEC como, por exemplo, a falta da remuneração aos participantes pelo tempo despendido na formação do PNAIC, a não impressão e distribuição dos cadernos do curso, a ausência de uma Coordenação Nacional responsável pela formação e pelo acompanhamento das ações do programa e, ainda, a redução da carga horária do curso, antes previsto para 120 horas presenciais. Dessa forma, o grupo reitera que o PNAIC não consiste em uma política de formação:

O fato de não propiciar esses aspectos destacados acima, reflete a desvalorização dos processos formativos na Educação Infantil, reverberando no envolvimento das professoras e explicitam a forma superficial, inconsistente e inadequada da inserção da pré-escola no PNAIC 2017/2018. (BAPTISTA, 2018).

Ora, se o PNAIC não constitui a política de formação de professores ambicionada pelo grupo organizador, certamente constitui a política de formação desejada pelo MEC. E preciso compreender que as disputas, o que está posto e o que está apagado nos documentos, os silêncios e os desvios não deixam também de delinear outra política de formação, alicerçada em valores que nem sempre são os esperados por aqueles que estão à frente das questões educacionais.

As problemáticas circunscritas acima, acerca da implementação do PNAIC na Educação Infantil, nos permitem pensar que ainda temos inúmeros desafios a serem superados para que uma formação que valorize a profissão docente e respeite sua autoria e seu protagonismo seja efetivamente implantada no país. Nesse sentido, importa-nos analisar ainda as imagens das professoras de Educação Infantil que se afiguram nesses projetos e documentos. Embora muitos deles tragam importantes contribuições em torno das pesquisas em educação, das práticas pedagógicas e dos saberes científicos, nem sempre colaboram para que a identidade docente da professora de Educação infantil tenha um cunho profissional, autônomo e emancipatório, conforme analisaremos adiante.

\section{A imagem da professora de educação infantil estampada nos cadernos de formação do PNAÍC}

Assumir a formação e o trabalho docente como uma atividade profissional requer escolhas e responsabilidade no que diz respeito ao tratamento dos conteúdos, aos discursos veiculados e ao preparo do material formativo. É preciso reconhecer que 
todo programa de formação cumpre finalidades específicas e manifesta, mesmo que implicitamente, determinadas representações de docência.

Louro (1997) ressalta que os discursos sociais produzem representações acerca das figuras da professora e do professor. A autora, ao analisar o processo de feminização do magistério, destaca que as representações ocorrem por meio de características e recursos empregados distintamente ao professor e à professora. Esse processo de representação não significa um mero reflexo das práticas desses sujeitos, mas sim, descrições que constituem e produzem o que é ser professora e professor.

Na mesma direção, Reis (1994) analisa os aspectos da construção do magistério feminino a partir de fotografias de normalistas entre o fim do século XIX e início do século XX e percebe o fotógrafo como uma das instâncias que também produzia representações sociais acerca da docência feminina. Nas imagens veiculadas, a autora destaca o quanto a professora era aproximada da figura religiosa e maternal. Abnegação e sacrifício eram qualidades a elas descritas, revelando a extensão, para a esfera da escola, de seu papel feminino no lar.

Se pensarmos nas diferentes esferas sociais que atuam na construção da profissão docente, podemos observar que o material do PNAIC da Educação Infantil constitui um dos meios de representação da imagem da professora, mais especificamente daquela que trabalha com crianças pequenas. Na tentativa de aproximá-la das propostas do Pacto, são usados, abundantemente, recursos como ilustrações infantis. Encontramos a justificativa desta escolha no "Caderno de Apresentação":

Por entendermos que o conteúdo atua pela forma e que esta também atua no conteúdo, buscamos neste material um projeto gráfico editorial bem-cuidado, com ilustrações de autores e ilustradores de referência no campo da literatura infantil (BRASIL, 2016a, p.14).

Essa assertiva nos permite questionar: o conteúdo e a forma escolhidos para o material produzem qual imagem de professora de Educação Infantil? Sua formação no PNAIC, acompanhada de personagens animados, tem como pressuposto uma concepção infantilizada de sua profissão?

Arroyo (2013), em suas reflexões acerca das imagens e autoimagens do ofício de mestre, afirma que cada grupo de professores tem um reconhecimento social, de acordo com o segmento em que atua. Tendo como objeto de análise os depoimentos de diversos professores acerca de sua profissão, o autor descreve que, em entrevistas de emprego para o cargo na Educação Infantil, uma das professoras percebeu que as características como amabilidade no trato e simpatia eram mais valorizadas do que seu percurso de formação acadêmica. Conforme identifica o autor, as professoras das séries iniciais do Ensino Fundamental, por sua vez, possuem outra imagem social, definida pela competência para o ensino das primeiras letras e dos números, além do carinho e da dedicação às crianças.

A maneira como os cadernos do PNAIC dirigem-se à professora de Educação Infantil sugere a necessidade de seu amparo e tutela, garantindo que seus pensamentos e ações sejam conduzidos pelos caminhos previstos pelos organizadores. Isso 
se evidencia através da utilização de artefatos como figuras de animais com balões de pensamentos, observações e definições de conceitos, os quais poderiam ser substituídos por notas de rodapé, por exemplo. Por outro lado, nos cadernos destinados aos docentes do Ensino Fundamental, notamos a inexistência de tais recursos e ilustrações infantis.

Quando nos deparamos com esses elementos usados especificamente no material da Educação Infantil, percebemos, conforme identifica Arroyo (2013), uma tensão entre as imagens sociais da profissão docente, as imagens pretendidas pela própria categoria e as autoimagens que cada profissional faz de si. É necessário, dessa maneira, confrontar os estereótipos que perpetuam o imaginário de professora primária vinculado à figura da mulher bondosa, tenra, pueril e cuidadosa.

Uma política de formação que dá indícios de que os saberes docentes não existem, expressa uma crença prévia de que os(as) educadores(as) não são capazes de pensar, avaliar e refletir, elaborando e dando novos significados ao conhecimento e à sua prática. Ademais, generaliza-se a ideia de que os(as) docentes(as) são mal formados e precisam de alguém que lhes ensine, desconsiderando, na verdade, que não há um saber absoluto (EMILIÃO, 2017).

Essa problemática manifesta-se também em um convite feito aos professores no "Caderno de Apresentação". Os editores utilizam uma epígrafe de Ligia Cademartori como abertura do material e reafirmam a importância do conteúdo do PNAIC: (... "Nosso suposto saber será abalado, e, se tivermos sorte, haverá lugar para a formulação de hipóteses novas. Não voltaremos para casa com a mesma bagagem." (BRASIL,2016a, p.11). Quando nos deparamos com o convite cujo discurso presume que o saber do(a) educador(a) é pensado como suposto, percebemos o quanto essa suposição já designa um ponto de vista formado e sem comprovação, menosprezando o percurso acadêmico e as experiências pessoais vividas por cada professor(a) até o momento de sua participação no PNAIC. Essa concepção acredita, ainda, que os (as) educadores(as) trocarão suas bagagens por outras mais inovadoras oferecidas pelo material, como se o conhecimento fosse peças a serem consumidas e descartadas.

Diversos discursos manifestados em textos e imagens sugerem que os(as) profissionais da educação infantil necessitam de meios que facilitem seu entendimento, desconsiderando seus saberes e sua capacidade reflexiva e ativa na produção de conhecimento acerca de seu trabalho. Nos trechos abaixo retirados do caderno 6, "Crianças como leitoras e autoras", observamos que o material dirige aos(às) docentes diversas perguntas, como se estes(as) prescindissem delas para pensarem:

E você? Tomando o que você pensava de currículo antes de estudar esta unidade e o que você pensa de currículo agora, em que aspectos você julga ter conseguido avançar? Que pontos sobre a temática do currículo ficaram mais claros para você? Que novas possibilidades de ação pedagógica na Educação Infantil você pode apontar? (BRASIL, 2016c, p.41).

Podemos aqui considerar o texto escrito tal qual propõe Certeau, (1994), como um lugar habitável por si próprio. A leitura, para ele, nos introduz numa arte 
que não é a passividade, o que significa que a própria atividade leitora é um lugar ativo e reflexivo, pois permite ao leitor não apenas passar seu olhar através da página, mas reapropriar-se do texto do outro, fazendo dele um lugar habitável (CERTEAU, 1994). Diante disso, cabe-nos problematizar a necessidade de um material formativo trazer uma sequência de perguntas predefinidas aos professores(as), como se somente assim estivesse garantido que sua leitura fosse de fato reflexiva. Por outro lado, considerando que o material tem como propósito servir a um sistema de formação em cascata, podemos analisar se as perguntas não estariam ali empregadas também para a orientação do formador responsável pela condução dos diálogos entre suas turmas.

É possível, nesse caso, perceber o quanto as perguntas coadunam com o desejo de conduzir a reflexividade docente para aquilo que se deseja obter como resultados da formação, como se o (a) professor(a) que os alcançassem estivesse exercendo, de fato, um “(...) compromisso ético e político com o outro", conforme postula o caderno 5, "Currículo e linguagem na educação infantil" (BRASIL, 2016b, p. 21).

Nosso desejo é que, ao final desta unidade, você possa: compreender a importância de observar e documentar as interações cotidianas das crianças; considerar o planejamento como recurso para organizar o cotidiano e também abrir espaço para a expressão das crianças; compreender o lugar da intenção pedagógica e a perspectiva do encontro pedagógico na proposta de uma educação humanizadora (BRASIL, 2016c, p. 52).

Os discursos que sustentam a implementação do PNAIC na Educação Infantil desconsideram a gama complexa de fatores que interferem na qualidade da educação e promovem ações de controle do processo pedagógico e dos fazeres docentes. Veiculam, ainda, a ideia de que apenas com a conscientização dos(as) professores(as) e sua adesão ao chamado nacional pela alfabetização é que o problema do analfabetismo poderá ser resolvido no Brasil. Torna-se urgente, assim, ampliarmos as possibilidades de ação para além daquelas que o material se propõe, ações essas que há décadas já fazem parte das pautas de reivindicação de diversos grupos e movimentos sociais ${ }^{6}$ que lutam pela defesa dos direitos das crianças e pela valorização da profissão docente na Educação Infantil, demandas que ainda não foram plenamente atendidas pelo poder público.

\section{Considerações finais}

No decorrer desse artigo, analisamos o processo de implementação do Pacto Nacional pela Alfabetização na Idade Certa (PNAIC) na Educação Infantil, tendo como base os materiais de formação do programa e os principais dilemas envolvidos em sua execução. Consideramos que as atuais políticas de formação de professores(as) nem sempre respeitam as especificidades de cada uma das etapas da Educação Básica, imprimindo a elas um modo de aprender e de ensinar no qual ritmos, tempos, conteúdos e resultados passam pelo controle de organismos externos que nem sempre conhecem as demandas dos que vivenciam cotidianamente os espaços educativos com as crianças pequenas. 
Nas análises realizadas, tecemos algumas proposições acerca dos perigos da escolarização da educação infantil, levando em conta o histórico de lutas dos diversos grupos sociais a favor de um atendimento de qualidade aos bebês e às crianças pequenas. Repensar as estruturas físicas, as formas de avaliação, a construção dos projetos pedagógicos, os critérios de qualidade e a valorização docente no trabalho em creches e pré-escolas são ações necessárias a serem tomadas tanto pelo poder público quanto pela sociedade.

A formação de professores(as) alfabetizadores(as) delineadas em um pacto nacional nem sempre considera a diversidade de práticas cotidianas com as crianças pequenas, deixando de valorizar seus protagonismos e a autoria docente em detrimento de uma avaliação em larga escala. Nos materiais analisados do PNAIC, percebemos diversos discursos que produzem representações acerca da docência feminina. Os desenhos empregados em quase todas as páginas do material funcionam como figuras de identificação, por meio dos quais a professora enxerga a si mesma, seu trabalho e as crianças. A densidade e a extensão do material, bem como a complexidade teórica são atenuadas pelos personagens ilustrados, os quais desejam provocar, na professora de Educação Infantil, sentimentos como alegria, ludicidade e encantamento, de modo igual ao que é esperado de seus alunos.

Ao assumirmos a busca pela redefinição do fazer docente, defendemos que a reflexividade seja garantida por meio da autonomia, da pluralidade de ideias e concepções, do acesso aos conhecimentos e à pesquisa, bem como dos processos democráticos e participativos nas escolas. Repensar, ainda, uma política de alfabetização, requer considerar que os sujeitos envolvidos no processo educativo não sejam apenas fluentes na língua e na matemática, mas também capazes de se apropriar desses conhecimentos em busca de sua emancipação.

Desejamos, assim, colaborar para que qualquer pacto pela educação seja um compromisso de luta contra as desigualdades na educação pública e a favor de melhores condições salariais e de trabalho nas escolas, não esquecendo de que a qualidade no atendimento de nossas crianças consolida-se por meio de investimentos e esforços do Estado e do comprometimento da sociedade em geral.

\section{Referências}

ARROYO, Miguel Gonzáles. Ofício de mestre: imagens e auto-imagens. 15. ed. Petrópolis, RJ: Vozes, 2013.

BAPTISTA, Mônica Correia et al. Carta às professoras de educação infantil. Belo Horizonte, 6 fev. 2018. Disponível em: <http://www.projetoleituraescrita.com.br/acoes/carta-as-professoras-da-educacao-infantil/>. Acesso em 18 abr. 2018.

BRASIL. Ministério da Educação. Secretaria da Educação Básica. Diretrizes Curriculares Nacionais para a Educação Infantil. Brasília: MEC/SEB, 2009.

BRASIL. Secretaria de Educação Básica. Diretoria de Apoio à Gestão Educacional. Pacto nacional pela alfabetização na idade certa: formação do professor alfabetizador. Brasília, DF: 2012. 
BRASIL. Lei n.13.005, de 25 de junho de 2014. Aprova o Plano Nacional de Educação - PNE e dá outras providências. Diário Oficial da União, Brasília, DF, 26 jun. 2014. Disponível em: <https://www.planalto.gov.br/ccivil_03/_ato2011-2014/2014/1ei/113005.htm> Acesso em 18 abr. 2018.

BRASIL. Ministério da Educação, Secretaria de Educação Básica. Caderno de apresentação. Brasília, DF: 2016a. Disponível em: <http://pacto.mec.gov.br/materiais-listagem/itemlist/category/4-materiais-da-educacao-infantil> Acesso em 18 abr. 2018.

BRASIL. Ministério da Educação, Secretaria de Educação Básica. Currículo e linguagem na educação infantil. Brasília, DF: 2016b. Disponível em: <http://pacto.mec.gov.br/materiais-listagem/itemlist/category/4-materiais-da-educacao-infantil> Acesso em 18 abr. 2018.

BRASIL. Ministério da Educação, Secretaria de Educação Básica. Crianças como leitoras e autoras. Brasília, DF: 2016c. Disponível em: <http://pacto.mec.gov.br/materiais-listagem/ itemlist/category/4-materiais-da-educacao-infantil> Acesso em 18 abr. 2018.

BRASIL. Portaria n. 826, de 7 de julho de 2017. Dispõe sobre o Pacto Nacional pela Alfabetização na Idade Certa PNAIC, suas ações, diretrizes gerais e a ação de formação no âmbito do Programa Novo Mais Educação PNME. <http://pacto.mec.gov.br/images/pdf/legislacao/ portaria_mec_826_alterada.pdf> Acesso em: 13 abr. 2018.

CERISARA, Ana Beatriz. A produção acadêmica na área da Educação Infantil a partir da análise de pareceres sobre o Referencial Curricular Nacional da Educação Infantil: Primeiras aproximações. In: FARIA, A. L. G. e PALHARES, M. S. Educação Infantil Pós-LDB: Rumos e desafios. Campinas: Autores associados,1999. p. 19-50.

CERTEAU, Michel de. A invenção do cotidiano: 1, Artes de fazer. Petrópolis: Vozes, 1994.

DICKEL, Adriana. A Avaliação Nacional da Alfabetização no contexto do sistema de avaliação da educação básica e do Pacto Nacional Pela Alfabetização na Idade Certa: Responsabilização e Controle.Cad.CEDES,Campinas,v.36,n.99,p.193-206, ago.2016.Disponívelem <http://www. scielo.br/scielo.php?script=sci_arttext\&pid=S0101-32622016000200193\&lng=en\&nrm=iso >. Acesso em 13 abr. 2018.

EMILIÃO, Soymara Vieira. (DES) Formação continuada de professores no/do PNAIC: A potência do encontro subvertendo a lógica de homogeneização. Revista Communitas, Acre, v.1, n.2, p.398-415. jul-dez. 2017. Disponível em: <http://revistas.ufac.br/revista/index.php/ COMMUNITAS/article/view/1506/pdf> Acesso em 13 abr. 2018.

FERNANDES, Mônica Pinheiro. Algumas indagações acerca do PNAIC: a formação continuada em perspectiva. In: SALES, José Albio Moreira de Sales... [et al.] Didática e a prática de ensino na relação com a sociedade. Fortaleza: CE: EdUECE, 2015. p. 906-916. Disponível em: <http://www.uece.br/endipe2014/ebooks/livro3/> acesso em 15 abr. 2018.

FREITAS, Luiz Carlos de. Os reformadores empresariais da educação: da desmoralização do magistério à destruição do sistema público de educação. Educ. Soc., Campinas, v. 33, n.119, p.379-404, jun. 2012. Disponível em: <http://www.scielo.br/scielo.php?script=sci_arttext\&pi$\mathrm{d}=\mathrm{S} 0101-73302012000200004 \& \operatorname{lng}=$ pt\&nrm=iso $>$. Acesso em 13 abr. 2018.

KUHLMAN JR., Moysés. A proteção a Infância e a “assistência científica”. In: Kuhlmann Jr, M. Infância e Educação Infantil: uma abordagem histórica. Porto Alegre: Mediação, 1998.

KUHLMAN JR, Moysés. Educação Infantil e Currículo. In: In: FARIA, A. L. G. e PALHARES, M. S. Educação Infantil Pós-LDB: Rumos e desafios. Campinas: Autores Associados, 1999. p.51-66.

LOURO, Guacira Lopes. Gênero, sexualidade e educação: Uma perspectiva pós-estruturalista. São Paulo: Vozes, 1997. 
LUNA, Tatiana. Autoria docente em sala de aula: uma análise de situações de trabalho a partir de relatos de prática. Atos de Pesquisa em Educação, Blumenau, v. 11, n.1, p.201-224, jan./abr 2016. Disponível em: <: http://dx.doi.org/10.7867/1809-0354.2016v11n1p201-224>. Acesso em 13 abr. 2018.

REIS, Maria Candida Delgado. Guardiãs do futuro: imagens do magistério de 1895 a 1920 em São Paulo. In: BRUSHINI, Cristina e SORJ, Bila (orgs). Novos olhares: mulheres e relações de gênero no Brasil. São Paulo: Fundação Carlos Chagas; Marco Zero, 1994. p.111-132.

SOUSA, Sandra Záquia. Avaliação da educação infantil: propostas em debate no Brasil. Interaç̧ões, Lisboa, v. 10, n. 32, p.68-88, 2014. Disponível em: <http://revistas.rcaap.pt/interaccoes/ article/view/6349>. Acesso em: 13 abr. 2018.

STIEG, Vanildo; ARAÚJO, Vania Carvalho de. As políticas de alfabetização para a infância no Brasil: Algumas inquietações. Revista Brasileira de Alfabetização - ABAlf. Vitória, ES, v. 1 n. 5 p. 69-86 jan./jun. 2017. Disponível em: <http://abalf.org.br/revistaeletronica/index.php/ rabalf/article/view/194/146> Acesso em 13 abr. 2018.

\section{Notas}

${ }^{1}$ Conforme lembra Emilião (2017), a determinação de uma idade certa para a alfabetização plena das crianças não é uma orientação expressa no PNE e sim uma exigência daqueles que elaboraram o PNAIC.

${ }^{2}$ Vale ressaltar que a Portaria foi publicada no mês de julho, sendo este um período de férias ou recesso de professores, o que dificultou o acesso e o conhecimento dos profissionais aos objetivos do programa.

${ }^{3}$ Entre essas metas está a de atingir, até 2022, o índice do nível de qualidade educacional da média dos países da Organização para a Cooperação e Desenvolvimento Econômico (OCDE).

${ }^{4}$ A título de comparação, o Referencial Curricular Nacional da Educação Infantil, elaborado pelo MEC em 1998, possui cerca de 400 páginas. Um dos diversos pontos criticados pelos pareceristas que analisaram o material na ocasião de sua publicação foi o excesso de páginas, com texto cansativo e linguagem pouco objetiva, o que dificultaria o acesso e a compreensão por parte de todos os profissionais que atuam diretamente com as crianças. Já o texto das Diretrizes Curriculares Nacionais para a Educação Infantil (2009) foi escrito com uma linguagem mais direta e possui cerca de 34 páginas. Ver CERISARA, 1999.

${ }^{5} \mathrm{O}$ documento é assinado pelas professoras Mônica Correia Baptista, Rita de Cássia de Freitas Coelho, Vanessa Ferraz Almeida Neves e Angela Barreto (UFMG), Patrícia Corsino (UFRJ) e Maria Fernanda Rezende Nunes (UNIRIO) e está disponível em: http://www.projetoleituraescrita.com.br/acoes/carta-as -professoras-da-educacao-infantil/. Acesso em 18 abr. 2018.

${ }^{6}$ Podemos citar aqui o movimento feminista, o Movimento Interfóruns de Educação Infantil do Brasil (MIEIB), os Fóruns Estaduais e do Distrito Federal de Educação Infantil, a Associação Nacional de PósGraduação e Pesquisa em Educação (ANPED), o Centro de Estudos Educação e Sociedade - CEDES, dentre outros.

* Professora de Educação Infantil da Secretaria Municipal de Educação de Campinas e pesquisadora no Grupo FOCUS - Unicamp, Campinas, São Paulo, Brasil.

** Professora de Educação Infantil e formadora de professores na Secretaria Municipal de Educação de Campinas, Campinas, São Paulo, Brasil. 


\section{Correspondência}

Fernanda Theodoro Roveri - Secretaria Municipal de Educação de Campinas. Avenida Anchieta, no 200. CEP: 13.015-904. Campinas, São Paulo, Brasil.

E-mail: ferdth@yahoo.com.br - carolineduarte@hotmail.com

Recebido em 27 de abril de 2018

Aprovado em 04 de junho de 2018

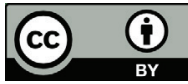

This work is licensed under a Creative Commons Attribution 4.0 International (CC BY 4.0). 